\title{
SEGMENTASI CITRA IKAN ARWANA SUPER RED BERDASARKAN DETEKSI TEPI MENGGUNAKAN ALGORITMA CANNY
}

\author{
Noviyanti $\mathrm{P}^{1}$, Kusrini ${ }^{2}$, Mei P. Kurniawan ${ }^{3}$ \\ ${ }^{1,2,3}$ Magister Teknik Informatika, Universitas AMIKOM Yogyakarta \\ Jl. Ring Road Utara, Kabupaten Sleman, Daerah Istimewa Yogyakarta \\ noviyanti.p@students.amikom.ac.id ${ }^{1}$, kusrini@amikom.ac.id ${ }^{2}$, meikurniawan@amikom.ac.id
}

\begin{abstract}
Ornamental fish is a fish that lived in the aquarium and for lovers of fish have ornamental fish is the most favored. One of the ornamental fish is pretty much in demand and has a fairly high selling price is super red Arowana fish. Super red Arowana fish also called dragon fish because it has scales resembling a dragon. In general, the selling price of super red Arowana fish is influenced by the size of the fish, such as the length and width of the fish. The high prices caused the farmers are very careful in treating the fish, so it is necessary there is a system that if it can measure the length and width of super red Arowana fish. The research groove generally consists of two phases. The initial phase of that region contributes to the best image segmentation and the second stage is to produce a long and wide super red Arowana fish. The current study focuses on the early stages, the best image segmentation. At this early stage, the detection process is carried out using the algorithm Canny edge of the fish so as to produce the best image segmentation. In this study, using three scenarios, the first scenario uses the Canny course, the second scenario using the canny and the median blur, the third scenario using the median blur and canny. Based on all these three scenarios obtained image segmentation fish with the best scenario, the scenario-2 using the canny and the median blur with MSE value of 26494.56, PNSR value of $41.89 \mathrm{~dB}$, and MAPE value of $99.28 \%$.
\end{abstract}

Keywords - Canny Edge Detection, Super Red Arowana Fish, Image Segmentation, Ornamental fish

Abstrak - Ikan hias merupakan ikan yang dihidupi didalam aquarium dan bagi para pecinta ikan memiliki ikan hias adalah hal yang paling disenangi. Salah satu ikan hias yang cukup banyak diminati dan memiliki harga jual yang cukup tinggi adalah ikan arwana super red. Ikan arwana jenis super red biasa juga disebut dengan ikan naga karena memiliki sisik yang menyerupai naga. Pada umumnya harga jual ikan arwana super red ini dipengaruhi oleh ukuran ikan, seperti panjang dan lebar ikan. Harga jual yang tinggi tersebut menyebabkan para pembudidaya sangat berhati-hati dalam memperlakukan ikan tersebut, sehingga dirasa perlu terdapat sebuah sistem yang sekiranya dapat mengukur panjang dan lebar ikan arwana super red. Alur penelitian secara umum terdiri dari dua tahap. Tahap awal yaitu meghasilkan segmentasi citra terbaik dan tahap kedua adalah menghasilkan panjang dan lebar ikan arwana super red. Penelitian yang dilakukan saat ini berfokus pada tahap awal, yaitu segmentasi citra terbaik. Pada tahap awal ini dilakukan proses deteksi tepi ikan menggunakan algoritma canny sehingga menghasilkan segmentasi citra terbaik. Pada penelitian ini menggunakan 3 skenario, skenario pertama menggunakan canny saja, skenario kedua menggunakan canny dan median blur, skenario ketiga menggunakan median blur dan canny. Berdasarkan ke-3 skenario tersebut diperoleh segmentasi citra ikan dengan skenario terbaik, yaitu skenario ke-2 menggunakan canny dan median blur dengan nilai MSE sebesar 26494.56, nilai PNSR sebesar 41.89 dB, dan nilai MAPE sebesar 99.28\%.

Kata kunci - Deteksi Tepi Algoritma Canny, Ikan Arwana Super Red, Segmentasi Citra, Ikan Hias

\section{PENDAHULUAN}

Budidaya perikanan merupakan salah satu usaha yang cukup menjanjikan. Salah satu budidaya perikanan yang memiliki peluang bisnis yang menjanjikan, yaitu budidaya ikan hias. Ikan hias merupakan ikan yang dihidupi didalam aquarium dan bagi para pecinta ikan memiliki ikan hias adalah hal yang paling disenangi.

Ikan arwana merupakan ikan hias yang banyak diminati walaupun memiliki harga yang cukup tinggi. Menurut Kepala Dinas Kabupaten Kapuas Hulu, ikan yang mampu diproduksi berkisar kurang lebih 31.000 ton dalam setiap tahunnya. Ikan tersebut terdiri dari ikan konsumsi dan ikan hias. Ikan-ikan tersebut di impor ke negera luar, yaitu negara Malaysia karena Kabupaten Kapuas Hulu merupakan Kabupaten yang berbatasan dengan negara Malaysia. Selain ikan konsumsi, ikan hias juga menjadi daya tarik bagi negara Malaysia, yaitu ikan arwana.

Tingginya harga ikan ini membuat para pembudidaya sangat berhati-hati dalam memperlakukannya. Pembudidaya perlu selalu melihat perkembangan dari ikan karena apabila ikan tersebut tidak dibudidaya dengan baik maka akan berdampak pada kualitas ikan tersebut. Pertumbuhan ikan menjadi salah satu hal yang perlu diperhatikan oleh para pembudidaya karena harga jual dari ikan ini juga dipengaruhi oleh ukuran ikan tersebut seperti panjang dan lebar, sehingga dirasa perlu dibuat sebuah sistem yang dapat membantu para pembudidaya dalam menentukan panjang dan lebar ikan secara otomatis.

Alur penelitian secara umum terdiri dari dua tahapan. Tahap awal yaitu menghasilkan segmentasi citra terbaik dan tahap kedua menghasilkan panjang dan lebar ikan. Namun pada penelitian yang dilakukan saat ini berfokus pada menghasilkan segmentasi citra terbaik karena hasil segmentasi citra terbaik ini yang 
akan membantu penelitian selanjutnya, yaitu menghasilkan panjang dan lebar ikan. Terdapat beberapa referensi yang dapat mendukung penelitian ini.

Penelitian yang dilakukan oleh Islamadina dkk tentang "Estimasi Panjang dan Lebar Ikan Berdasarkan Visual Capture". Penelitian tersebut dilakukan untuk mempermudah pekerjaan manusia agar lebih efektif dan tidak memakan waktu yang lama. Pada penelitian yang dilakukan menggunakan metode deteksi Blob. Keakuratan yang diperoleh dari penelitian tersebut sebesar $80 \%$ [1].

Penelitian yang dilakukan oleh Laxmi dkk tentang "Analisis Perbandingan Metode Prewitt dan Canny untuk Identifikasi Air Tawar". Pada penelitian ini dilakukan perbandingan metode untuk mengenali jenis ikan air tawar berdasarkan titik tepi ikan. Berdasarkan penelitian yang telah dilakukan, metode canny dapat memberikan hasil deteksi tepi ikan dengan lebih jelas. Penggabungan kedua metode tersebut dapat digunakan juga dari prewitt ke canny. Deteksi tepi menggunakan canny dapat menyempurnakan deteksi tepi menggunakan prewitt [2].

Penelitian yang dilakukan oleh Mustafid dan 'Uyun tentang "Segmentasi Citra Sapi Berbasis Deteksi Tepi Menggunakan Algoritma Canny Edge Detection". Penelitian ini merupakan penelitian tahap awal sebelum menentukan bobot sapi. Hasil penelitian ini berupa segmentasi citra sapi dengan menggunakan 5 skenario. Berdasarkan hasil evaluasi skenario yang telah dilakukan diperoleh skenario terbaik adalah skenario ke-3 (median blur dan canny) dengan MSE sebesar 230.051 dan PNSR sebesar 24.524 dB [3].

Penelitian yang dilakukan oleh Gunawan dkk tentang "Mobile Application Detection of Road Damage using Canny Algorithm". Hasil dari penelitian ini adalah algoritma canny dapat digunakan untuk mendeteksi kerusakan jalan dengan menambahkan fungsi threshold [4].

Penelitian yang dilakukan oleh Kirti tentang "Image Segmentation using Canny Edge Detection Technique". Pada penelitian ini melakukan segmentasi sebuah citra dengan menggunakan algoritma canny. Dijelaskan pula proses atau langkah dari algortima canny, yaitu melakukan smoothing, menemukan gradients, non-maxima suppression, double thresholding, dan edge tracking by hysteresis [5].

\section{A. Budidaya Arwana}

Ikan arwana jenis super red dapat memiliki nilai jual yang tinggi apabila tidak memiliki cacat pada bagian sisik dan juga punggung, sehingga pada umumnya para pembudidaya mengukur panjang dan lebar ikan dengan dikira-kira karena apabila diukur secara manual dikhawatirkan dapat merusak sisik dan melukai punggung dan biasa juga pembudidaya membius untuk mengukur ikan agar ikan tidak banyak bergerak namun dikhawatirkan dapat mempengaruhi kesehatan ikan [6]. Hal ini yang menjadi dasar perlunya proses segmentasi untuk dapat mengetahui panjang dan lebar ikan arwana yang akan dilakukan pada penelitian selanjutnya. Pada penelitian ini hal yang utama dan penting untuk dihasilkan adalah segmentasi citra terbaik dengan berdasarkan pada tiga skenario.

\section{B. Metode Operator Canny}

Metode yang digunakan pada penelitian ini adalah metode pendeteksian tepi dengan menggunakan metode deteksi tepi operator canny. Metode deteksi tepi operator canny dapat menghasilkan garis tepi dengan tingkat ketebalan yang cukup teliti, yaitu sebesar 1 piksel. Karena tingkat ketebalan dan ketelitian deteksi tepi operator canny ini diharapkan agar dapat menghasilkan bagian dari citra digital ikan tersebut dan akhirnya dapat menghasilkan ukuran panjang dan lebar ikan arwana [7]. Metode Operator Canny yang digunakan secara umum terdiri dari 4 langkah, yaitu sebagai berikut [8]:

a. Penghalusan citra menggunakan filter gaussian yang bertujuan untuk mengurangi noise. Matriks filter gaussian ditunjukkan seperti pada matriks berikut :

\begin{tabular}{|c|c|c|c|c|c|}
\hline \multirow{3}{*}{$\frac{1}{159}$} & 2 & 4 & 5 & 4 & 2 \\
\hline & 4 & 9 & 12 & 9 & 4 \\
\hline & 5 & 12 & 15 & 12 & 5 \\
\hline \multirow[t]{2}{*}{159} & 4 & 9 & 12 & 9 & 4 \\
\hline & 2 & 4 & 5 & 4 & 2 \\
\hline
\end{tabular}

b. Menghitung besaran magnitude (kekuatan garis tepi) dan orientation (arah garis tepi) dengan menggunakan operator sobel dengan persamaan 3 dan 4 berikut, dengan $M[i, j]$ adalah magnitude dan $\theta[i, j]$ adalah orientation, rumus magnitude dan orientation dapat dilihat pada persamaan 1 dan 2 .
$M[i, j]=\sqrt{P[i, j]^{2}+Q[i, j]^{2}}$
$\Theta[i, j]=\arctan (Q[i, j], P[i, j])$

c. Non-maximum suppression, bertujuan untuk menghasilkan garis tepi yang tepat dan pada dasarnya non-maximum suppression mencari titik tertinggi pada data besaran tepi yang diperoleh dengan menggunakan informasi arah tepi untuk memeriksa apakah titik tersebut berada pada puncak punggung bukit (ridge).

d. Langkah terakhir adalah hysteresis thresholding. Pada proses ini terdapat 3 aturan, yaitu apabila gradien pada sebuah piksel diatas nilai ambang batas (high) maka piksel tersebut merupakan tepi piksel, apabila gradien pada sebuah piksel dibawah nilai ambang batas (low) maka piksel tersebut bukan tepi piksel, dan yang terakhir apabila gradien pada sebuah piksel berada diantara nilai ambang batas (high dan low) maka piksel tersebut termasuk tepi piksel dengan catatan piksel tersebut terhubung dengan sebuah tepi piksel secara langsung atau melalui piksel-piksel antara "low" dan "high". Hasil deteksi tepi dengan menggunakan algoritma canny dapat dilihat pada Gambar 1. 


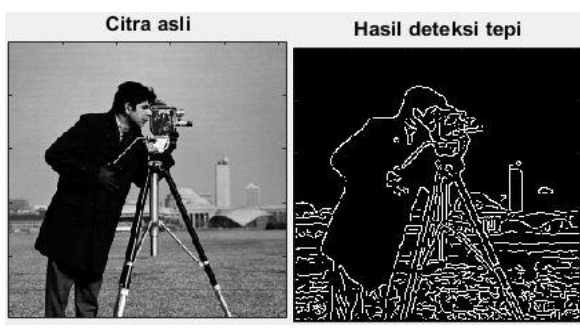

Gambar 1. Hasil Deteksi Tepi menggunakan Algoritma Canny

\section{Median Blur}

Median blur merupakan salah satu bagian penghalusan citra yang terdapat pada median filter. Median filter merupakan salah satu metode yang efektif dalam mengurangi noise pada sebuah citra. Misalnya terdapat citra input sebagai berikut [9]:

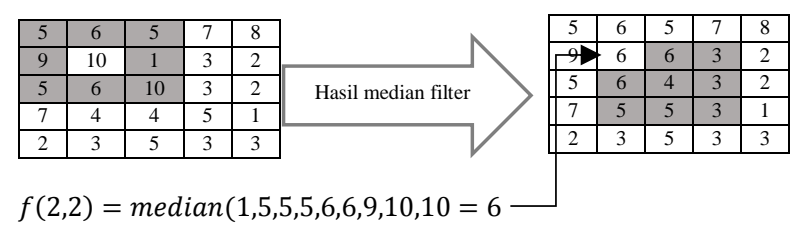

D. Perhitungan Menentukan Panjang dan Lebar

Tahap awal pada penelitian ini adalah processing data dengan melakukan segmentasi citra dan tahap selanjutnya adalaha untuk menentukan panjang dan lebar ikan arwana super red berdasarkan hasil deteksi tepi dengan 3 skenario dimana tiap deteksi tepi tersebut menghasilkan nilai 0 dan 1.1 dengan hasil tepi berwarna putih mengindikasikan objek dan 0 dengan hasil tepi berwarna hitam mengindikasikan bukan objek. Perhitungan panjang dan lebar ikan arwana super red berdasarkan pada vektor kolom dan vektor baris matriks yang memuat nilai 1 . Perhitungan ini perlu untuk dipaparkan karena akan menjadi acuan dalam menentukan MSE, PSNR, dan MAPE. Perhitungan menentukan panjang dan lebar ikan arwana super red menggunakan persamaan 3 dan 4 .

Panjang $=$ vektor kolom max - vektor kolom $\min (3)$

Lebar $=$ vektor baris max - vektor baris min

\section{E. MSE}

MSE merupakan singkatan dari Mean Square Error atau rata-rata eror. MSE dan PSNR merupakan salah satu teknik dalam menentukan kualitas dari sebuah citra [10]. MSE pada penelitian ini digunakan untuk melihat nilai perbedaan dari citra awal dengan citra hasil deteksi tepi. Pada penelitian ini nilai MSE terbesar mengindikasikan hasil tepi yang diperoleh dapat menunjukkan tepi dalam mengenali objek pada citra. Rumus untuk menentukan nilai MSE dapat dilihat pada persamaan 5 .

$M S E=\frac{1}{m * n} * \sum_{x=0}^{m-1} \sum_{y=0}^{n-1}[i(x, y)-j(x, y)]^{2}$

\section{F. PSNR}

PSNR merupakan singkatan dari Peak Signal to
Noise Ratio. PSNR merupakan evaluasi citra yang digunakan untuk mengindikasikan noise yang berpengaruh pada sebuah citra berdasarkan MSE. Pada penelitian ini semakin kecil PSNR maka akan semakin baik hasil rekonstruksi citra dalam mengenali objek pada citra. Rumus menentukan PSNR dapat dilihat pada persamaan 6 .

$P S N R=10 \log _{10} \frac{255^{2}}{M S E}$

\section{G. MAPE}

MAPE merupakan singkatan dari Mean Absolute Percentage Error. Dalam penelitian ini nilai persentase eror terbesar terhadap 3 skenario merupakan segmentasi terbaik untuk menentukan panjang dan lebar ikana arwanan super red. Rumus perhitungan MAPE dapat dilihat pada persamaan 7.

MAPE $=\sum_{x=0}^{m-1} \sum_{y=0}^{n-1}\left(\left|\frac{i(x, y)-j(x, y)}{i(x, y)}\right| 100 \%\right)$

\section{METODE PENELITIAN}

Alur penelitian secara umum dapat dilihat pada Gambar 2. Gambar 2 merupakan alur penelitian secara umum untuk menentukan panjang dan lebar ikan arwana super red. Namun penelitian yang dilakukan saat ini berfokus pada tahap awal, yaitu segmentasi citra ikan arwana super red. Tahap awal ini perlu dilakukan untuk menghasilkan segmentasi citra terbaik.

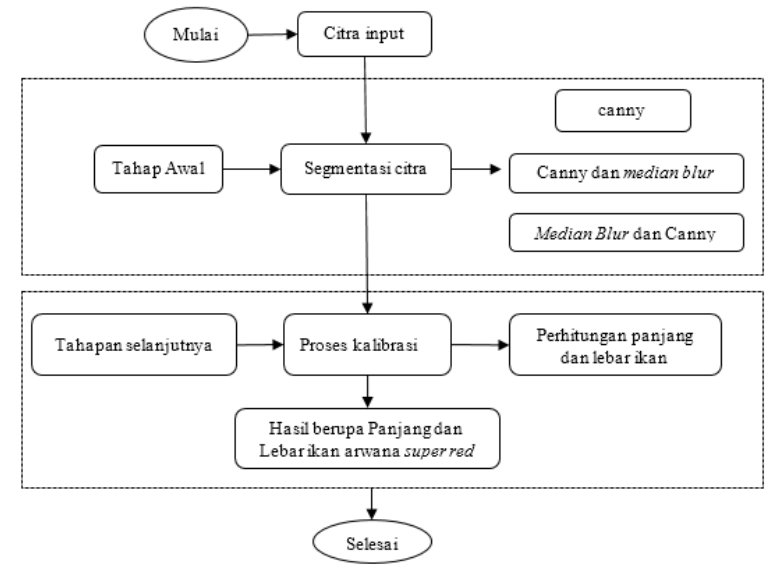

Gambar 2. Alur Penelitian Secara Umum

Jenis penelitian yang dilakukan adalah eksperimen. Pada penelitian ini dilakukan dengan mengambil foto ikan diaquarium. Keadaan ikan bergerak dan kemudian difoto dengan melihat posisi ikan merupakan eksperimen yang akan dilakukan pada penelitian ini sehingga dapat menghasilkan segmentasi citra dari ikan arwana super red tersebut dengan menggunakan 3 skenario. Adapun langkah yang dilakukan untuk menghasilkan segmentasi citra pada penelitian ini dapat dilihat pada Gambar 3. Alur segmentasi citra dijabarkan dengan beberapa tahapan berikut. 


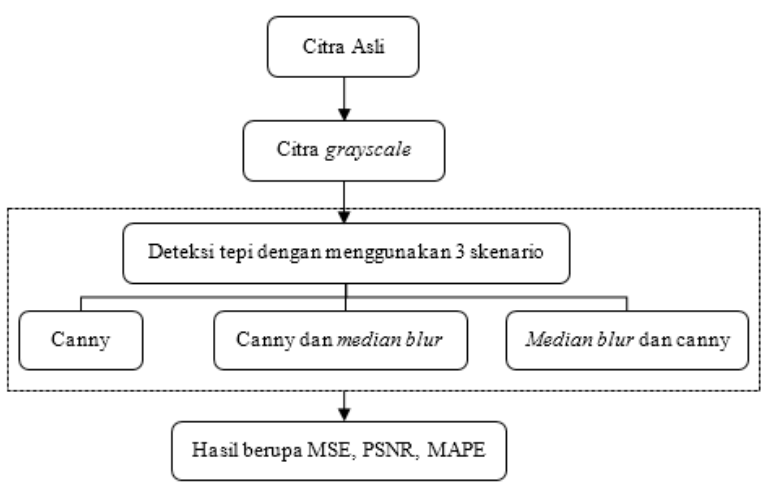

Gambar 3. Proses Menghasilkan Segmentasi Citra

1. Pengumpulan Data

Proses pengumpulan data dengan mengambil foto ikan yang berada pada aquarium. Pengambilan citra atau gambar ikan menggunakan handphone ZenFone Max Pro M1 konfigurasi kamera belakang 13 megapiksel dan menggunakan bantuan tripod. Untuk pengambilan citra atau gambar ikan dilakukan dengan jarak dari kamera ke aquarium adalah $20 \mathrm{~cm}$ dengan posisi kamera landscape. Untuk jarak dari dinding aquarium ke ikan dilihat jarak yang paling akurat dengan catatan ikan tidak berada terlalu jauh dari dinding aquarium. Data yang digunakan pada penelitian ini terdiri dari 10 data ikan arwana super red. Data ikan yang digunakan dapat dilihat pada Gambar 4.

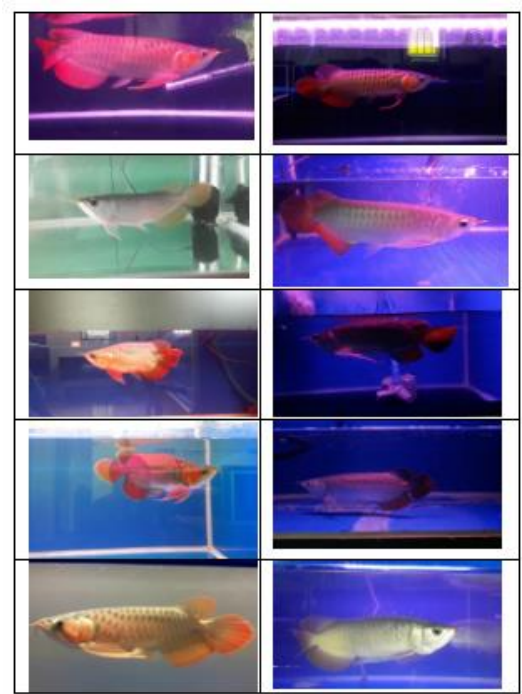

Gambar 4. Data Ikan Arwana Super Red
2. Preprocessing Data

Preprocessing data yang dilakukan untuk memperoleh segmentasi citra ikan arwana super red. Untuk preprocessing yang dilakukan dengan mengkonversi citra asli ke citra grayscale terlebih dahulu. Setelah diubah menjadi citra grayscale kemudian diproses dengan menggunakan deteksi tepi algoritma canny. Pada proses deteksi tepi akan digunakan 3 skenario, yaitu deteksi tepi dengan menggunakan canny saja, deteksi tepi dengan menggunakan canny dan median blur, dan deteksi tepi menggunakan median blur dan canny.

3. Perbandingan nilai MSE, PSNR, dan MAPE

Setelah diperoleh hasil segmentasi citra berdasarkan ketiga skenario tersebut dilakukan perhitungan untuk melihat perbandingan nilai MSE, PSNR, dan MAPE pada tiap skenario.

4. Penarikan Kesimpulan

Nilai MSE pada penelitian ini diambil nilai terbesar karena mengindikasikan nilai eror dengan garis tepi yang lebih sedikit, nilai PSNR terkecil karena mengindikasikan segmentasi yang tepat untuk kasus ini, dan nilai MAPE terbesar karena mengindikasikan garis tepi yang lebih sedikit yang ditunjukkan dalam bentuk persentase eror terbesar.

\section{HASIL DAN PEMBAHASAN}

Penelitian yang dilakukan untuk meghasilkan segmentasi citra terbaik menggunakan tiga skenario. Ketiga skenario tersebut akan dibandingkan dan akan diperoleh skenario dengan segmentasi citra terbaik dan tepat untuk kasus pada penelitian ini. Skenario pengujian dapat dilihat pada Tabel 1.

Tabel 1. Skenario Pengujian

\begin{tabular}{|c|c|}
\hline No & Skenario \\
\hline 1 & Canny \\
\hline 2 & Canny dan Median Blur \\
\hline 3 & Median Blur dan Canny \\
\hline
\end{tabular}

Tabel 1 merupakan skenario pengujian yang digunakan pada penelitian ini, yaitu menggunakan canny, canny dan median blur, median blur dan canny. Berdasarkan ketiga skenario pengujian yang telah dilakukan tersebut, diperoleh hasil deteksi tepi yang dapat dilihat pada Gambar 5. 


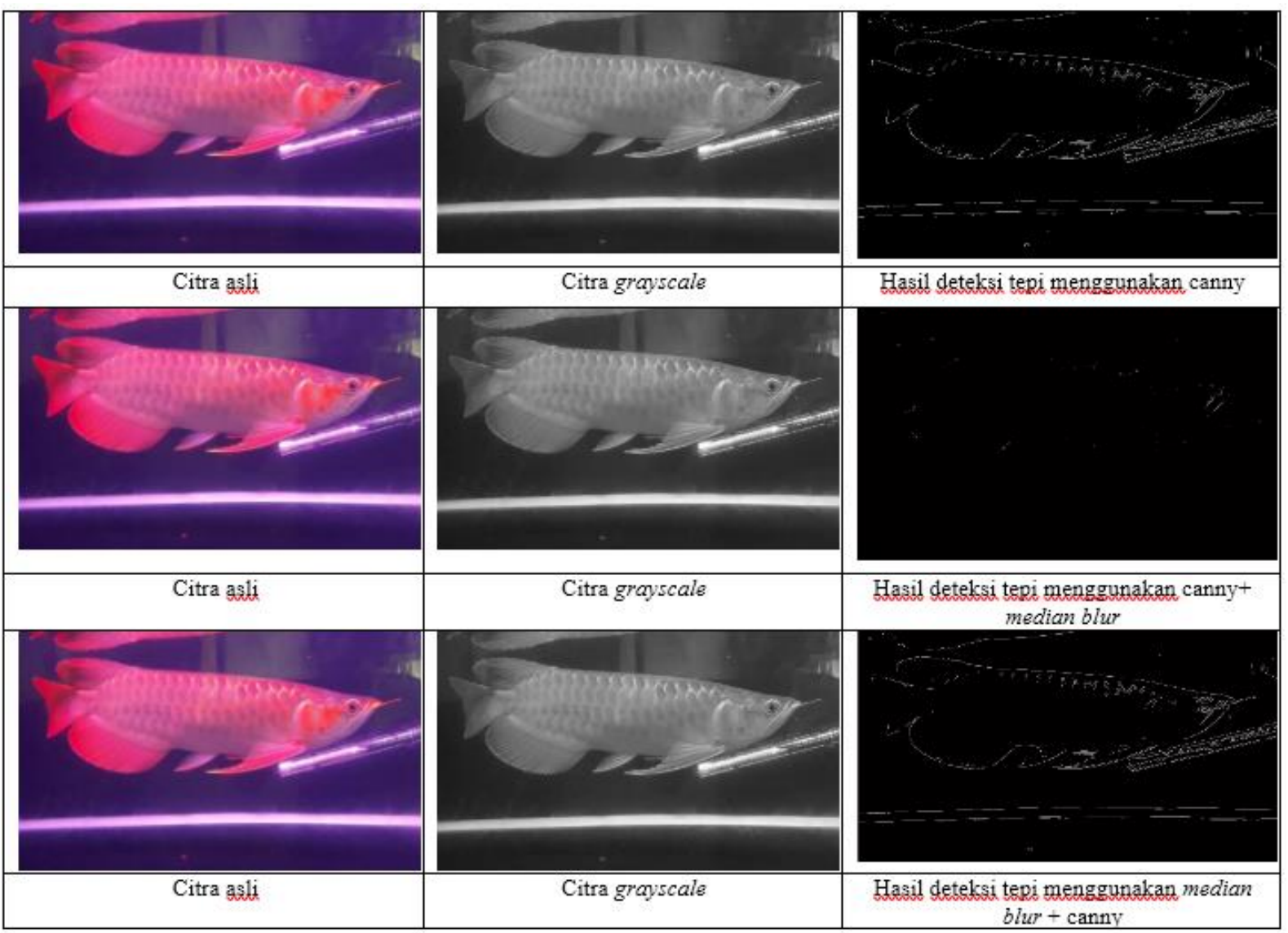

Gambar 5. Hasil Deteksi Tepi menggunakan 3 Skenario

Gambar 5 merupakan hasil deteksi tepi dengan menggunakan 3 skenario pengujian. Skenario pertama adalah menggunakan canny. Untuk algoritma canny menggunakan nilai threshold low sebesar 0.075 dan threshold high sebesar 0.175. Script pada bagian penggunaan threshold dengan menggunakan canny saja yang digunakan pada penelitian ini dapat dilihat pada listing 1 .

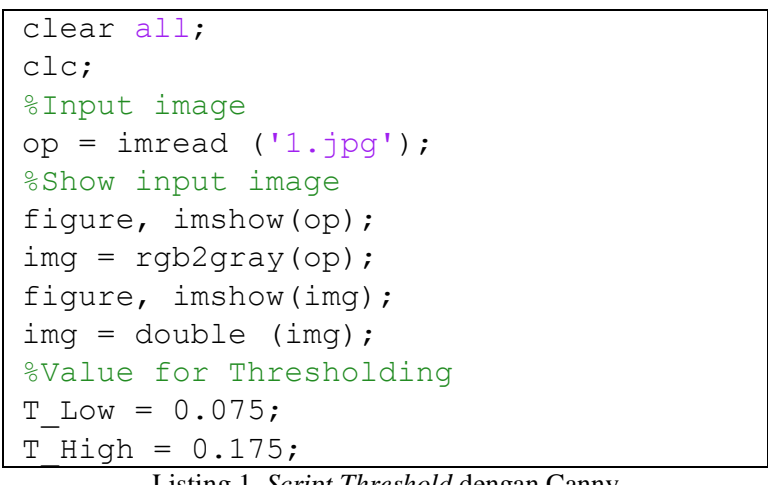

\section{Listing 1. Script Threshold dengan Canny}

Pada skenario kedua menggunakan canny dan median blur dengan algoritma canny menggunakan nilai threshold low sebesar 0.075 dan threshold high sebesar 0.175, sedangkan untuk median blur menggunakan median filter $3 \times 3$. Pada penelitian ini menggunakan nilai threshold yang sama, yaitu nilai threshold low sebesar 0.075 dan threshold high sebesar
0.175. Perbedaannya adalah untuk skenario kedua menggunakan algoritma canny yang ditambahkan dengan median filter sebesar $3 \times 3$. Untuk script skenario kedua dapat dilihat pada listing 2 .

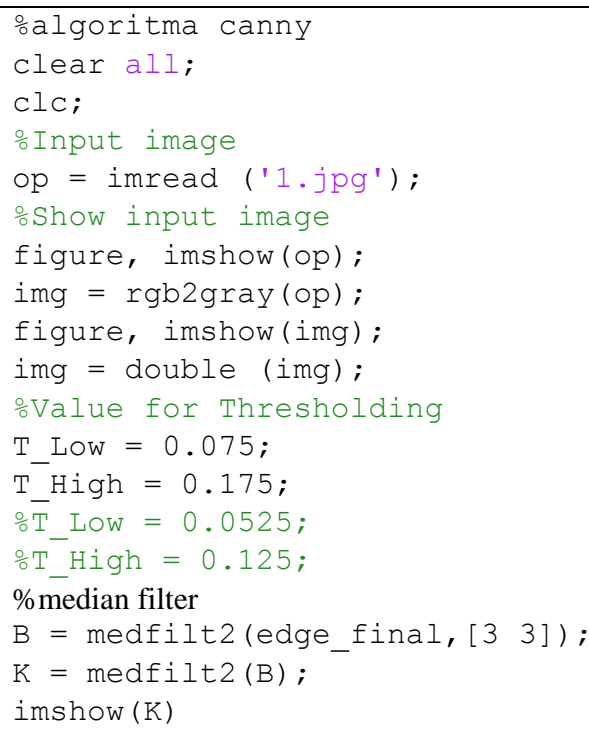

Listing 2. Script Threshold Canny dan Median Blur

Skenario ketiga menggunakan median blur dan canny dengan menggunakan median filter $3 \times 3$ dan 
untuk algoritma canny menggunakan nilai threshold low sebesar 0.075 dan threshold high sebesar 0.175. Skenario ketiga menggunakan median filter terlebih dahulu setelah itu melakukan deteksi tepi menggunakan algoritma canny. Script dapat dilihat pada listing 3 .

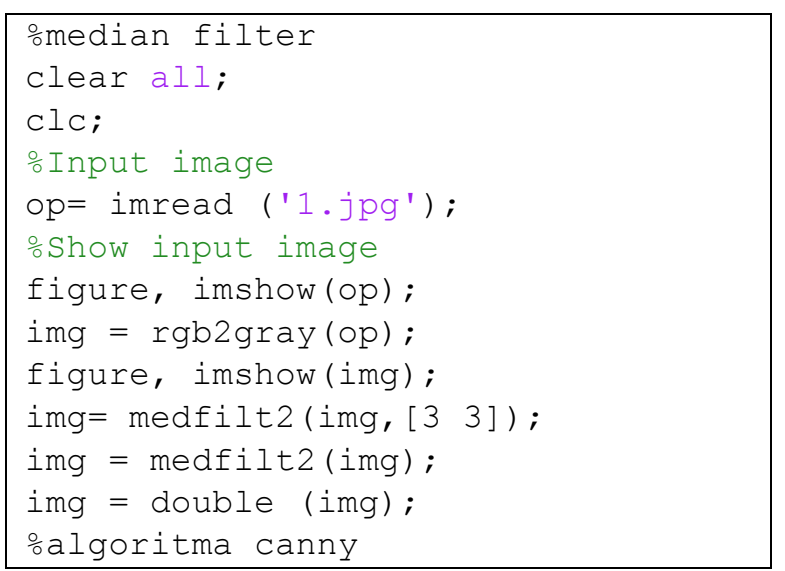

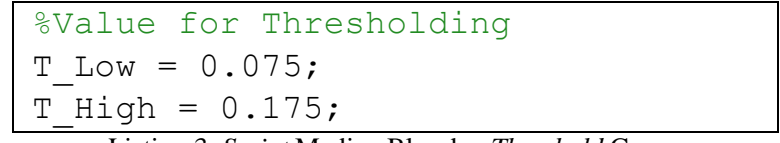

Listing 3. Script Median Blur dan Threshold Canny

Penggunaan threshold baik digunakan pada penelitian ini seperti yang dilakukan [4]. Nilai threshold dapat mempengaruhi tepi dan dapat membantu untuk mengurangi noise.

Berdasarkan segmentasi citra yang telah dilakukan menggunakan 3 skenario tersebut diperoleh nilai MSE, PSNR, dan MAPE pada tiap skenario yang dapat dilihat pada Tabel 2.

Tabel 2. Nilai MSE, PSNR, dan MAPE

\begin{tabular}{|c|r|r|r|r|r|r|r|r|r|}
\hline \multirow{2}{*}{ Data ke- } & \multicolumn{4}{|c|}{ canny } & \multicolumn{3}{c|}{ canny dan median blur } & \multicolumn{3}{c|}{ median blur dan canny } \\
\cline { 2 - 10 } & \multicolumn{1}{|c|}{ MSE } & PSNR & MAPE & MSE & PSNR & MAPE & MSE & PSNR & MAPE \\
\hline 1 & 13429.00 & 65.85 & 0.98 & 28823.00 & 28.89 & 1.00 & 13447.67 & 66.18 & 0.99 \\
\hline 2 & 13113.67 & 52.07 & 0.98 & 40997.67 & 30.61 & 1.00 & 41243.00 & 30.77 & 0.99 \\
\hline 3 & 11050.67 & 156.00 & 0.99 & 16174.67 & 40.55 & 1.00 & 16134.33 & 40.64 & 1.00 \\
\hline 4 & 22838.33 & 31.72 & 0.97 & 23213.67 & 31.20 & 0.99 & 23137.67 & 31.29 & 0.98 \\
\hline 5 & 16551.67 & 39.67 & 0.99 & 10346.00 & 133.16 & 1.00 & 10336.33 & 133.72 & 0.99 \\
\hline 6 & 23187.33 & 28.63 & 0.99 & 23276.67 & 28.52 & 1.00 & 23214.33 & 28.59 & 1.00 \\
\hline 7 & 39420.33 & 146.05 & 0.98 & 43952.00 & 21.41 & 1.00 & 44001.00 & 21.62 & 0.99 \\
\hline 8 & 6992.00 & 259.26 & 0.96 & 40342.56 & 23.87 & 0.97 & 18572.00 & 35.63 & 0.96 \\
\hline 9 & 20300.33 & 32.42 & 0.98 & 18750.33 & 34.76 & 0.98 & 20188.67 & 32.57 & 0.98 \\
\hline 10 & 18966.67 & 46.03 & 0.99 & 19069.00 & 45.90 & 1.00 & 18968.00 & 46.07 & 0.99 \\
\hline
\end{tabular}

Tabel 2 merupakan nilai perhitungan MSE, PSNR, dan MAPE yang diperoleh berdasarkan pengurangan antara matriks citra asli dan matriks citra hasil deteksi tepi. Untuk citra asli digunakan nilai matriks pada kanal red, green, dan blue yang kemudian dirata-ratakan. Nilai MSE, PSNR, dan MAPE diujikan pada 3 skenario pengujian sehingga diperoleh hasil seperti pada Tabel 2. Berdasarkan Tabel 2 diatas, dapat dilihat perbandingan untuk nilai MSE, PSNR, dan MAPE pada setiap skenario pengujian dengan cara merata-ratakan nilai MSE, PSNR, dan MAPE pada tiap skenario. Untuk nilai MAPE setelah dirata-ratakan kemudian dikalikan dengan 100. Perbandingan nilai MSE, PSNR, dan MAPE pada penelitian ini dibuat dalam bentuk grafik yang dapat dilihat pada Gambar 6, 7 , dan 8 .

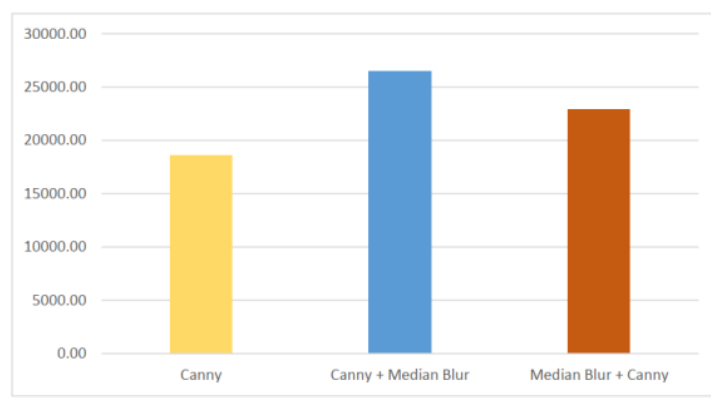

Gambar 6. Grafik Perbandingan Nilai MSE

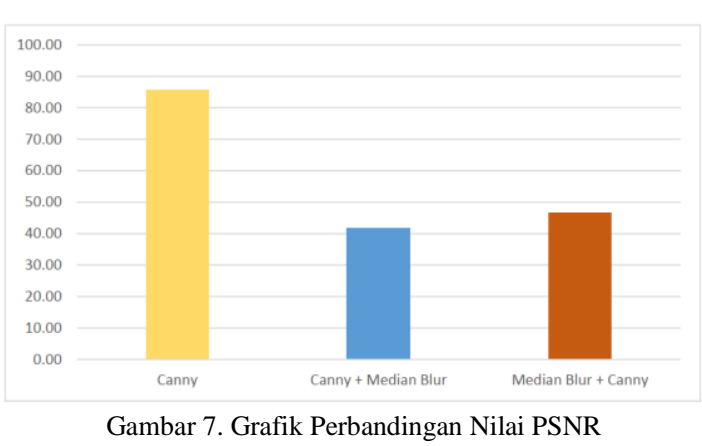

Gambar 7. Grafik Perbandingan Nilai PSNR 


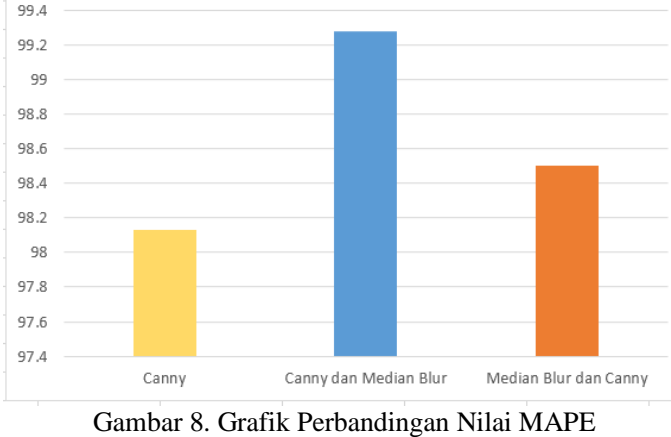

Gambar 6,7, dan 8 merupakan grafik perbandingan pada 3 skenario pengujian terhadap nilai MSE, PSNR, dan MAPE. Dalam menentukan nilai MSE menggunakan persamaan 5 , menentukan nilai PSNR menggunakan persamaan 6 , dan menentukan nilai MAPE menggunakan persamaan 7. Pada skenario pertama dengan menggunakan canny saja diperoleh nilai MSE sebesar 18585.00, nilai PSNR sebesar 85.77, dan nilai MAPE sebesar $98.13 \%$, pada skenario kedua dengan menggunakan canny dan median blur diperoleh nilai MSE sebesar 26494.56, nilai PSNR sebesar 41.89, dan nilai MAPE sebesar $99.28 \%$, dan pada skenario ketiga dengan menggunakan median blur dan canny diperoleh nilai MSE sebesar 22924.30, nilai PSNR sebesar 46.71, dan nilai MAPE sebesar 98.50\%. Pada penelitian ini nilai MSE terbesar, nilai PSNR terkecil, dan nilai MAPE terbesar merupakan nilai terbaik dalam menghasilkan segmentasi karena pada penelitian ini hasil deteksi tepi diharapkan dapat mengenali objek pada sebuah citra, sehingga background diharapkan untuk tidak terdeteksi. Oleh karena hal tersebut nilai MSE terbesar, nilai PSNR terkecil, dan nilai MAPE terbesar yang dianggap terbaik pada penelitian ini.

\section{KESIMPULAN}

Berdasarkan penelitian yang telah dilakukan maka dapat disimpulkan bahwa:

1. Skenario pengujian untuk menghasilkan segmentasi citra terbaik adalah skenario kedua dengan menggunakan canny dan median blur, dengan nilai MSE sebesar 26494.56, nilai PNSR sebesar $41.89 \mathrm{~dB}$, dan nilai MAPE sebesar 99.28\%. Pada penelitian ini nilai MSE terbesar, nilai PSNR terkecil, dan nilai MAPE terbesar merupakan nilai terbaik dalam menghasilkan segmentasi karena pada penelitian ini hasil deteksi tepi diharapkan dapat mengenali objek pada sebuah citra, sehingga background diharapkan untuk tidak terdeteksi. Oleh karena hal tersebut nilai MSE terbesar, nilai PSNR terkecil, dan nilai MAPE terbesar yang dianggap terbaik pada penelitian ini.

2. Penelitian tahap awal ini akan digunakan untuk tahap selanjutnya, yaitu menentukan panjang dan lebar ikan arwana super red. Pada penelitian tahap awal yang telah dilakukan ini pula dapat disimpulkan bahwa cahaya dapat mempengaruhi hasil deteksi tepi citra dan jarak pengambilan citra antara kamera dan objek diharapkan sama.

\section{SARAN}

Penelitian yang telah dilakukan masih memiliki kekurangan sehingga kedepannya dapat dikembangkan lebih lanjut terkait algoritma yang digunakan untuk mengenali objek pada citra dengan pengaruh cahaya yang tertangkap kamera. Jarak antara kamera dan objek perlu diperhatikan karena berpengaruh terhadap hasil segmentasi pada citra.

\section{DAFTAR PUSTAKA}

[1] R. Islamadina, N. Pramita, F. Arnia, and K. Munadi, "Estimasi Panjang dan Lebar Ikan Berdasarkan Visual Capture," Semin. Nas. dan Expo Tek. Elektro, pp. 97-101, 2017.

[2] G. F. Laxmi, P. Eosina, and F. Fatimah, "Analisis perbandingan metode prewitt dan canny untuk identifikasi ikan air tawar," Pros. SINTAK, pp. 201-206, 2017.

[3] A. Mustafid and S. 'Uyun, "Segmentasi Citra Sapi Berbasis Deteksi Tepi Menggunakan Algoritma Canny Edge Detection," J. Buana Inform., vol. 8, no. 1, pp. 27-36, 2017, doi: 10.24002/jbi.v8i1.1074.

[4] G. Gunawan et al., "Mobile Application Detection of Road Damage using Canny Algorithm," J. Phys. Conf. Ser., vol. 1019, no. 1, 2018, doi: 10.1088/17426596/1019/1/012035.

[5] Kirti and A. Bhatnagar, "Image Segmentation Using Canny Edge Detection Technique," vol. 04, no. 04, pp. 8-14, 2017.

[6] Y. Sudarto, Ikan Siluk Arwana Indonesia. KANISIUS, 2005.

[7] P. Hidayatullah, Pengolahan Citra Digital Teori dan Aplikasi Nyata. Bandung: Informatika Bandung, 2017.

[8] A. Hermawati, Fajar, Pengolahan Citra Digital Konsep dan Teori. Yogyakarta: Penerbit Andi, 2013.

[9] I. Maulana and P. N. Andono, "Analisa Perbandingan Adaptif Median Filter Dan Median Filter Dalam Reduksi Noise Salt \& Pepper," CogITo Smart J., vol. 2, no. 2, p. 157, 2016, doi: 10.31154/cogito.v2i2.26.157-166.

[10] H. R. Fajrin, "Perbandingan Metode Untuk Perbaikan Kualitas Citra Mammogram," Simetris J. Tek. Mesin, Elektro dan Ilmu Komput., vol. 7, no. 2, p. 657, 2016, doi: 10.24176/simet.v7i2.778. 